\title{
ANTERIOR SERVIKAL DISKEKTOMI VE FÜZYON UYGULANAN HASTALARDA KEMIK MINERAL YOĞUNLUĞUNUN FÜZYON VE FIKSASYON ÜZERINE ETKISI
}

\author{
IN PATIENTS UNDERGOING ANTERIOR CERVICAL DISCECTOMY AND FUSION \\ EFFECT OF BONE MINERAL DENSITY ON FUSION AND FIXATION
}

\section{Zafer ŞEN ${ }^{1}$, Serkan ERKAN ${ }^{2}$}

${ }^{1}$ Sağlık Bilimleri Üniversitesi Konya Eğitim ve Araştırma Hastanesi, Ortopedi ve Travmatoloji ABD

${ }^{2}$ Celal Bayar Üniversitesi, Tıp Fakültesi, Ortopedi ve Travmatoloji ABD

\section{Öz}

\section{Amaç}

Bu çalışmanın amacı, anterior servikal diskektomi ve füzyon uyguladığımız hastaların radyolojik ve klinik sonuçlarını karşılaştırmak ve füzyon oluşumu ile kemik mineral yoğunluğu arasındaki ilişkiyi saptamaktır.

\section{Gereç ve Yöntem}

Çalışmaya, Celal Bayar Üniversitesi Tıp Fakültesi Hastanesi Ortopedi ve Travmatoloji kliniğinde servikal dejeneratif disk hastalığı ve servikal spondiloz tanıları ile başvuran toplam 23 hasta dahil edildi. Olgular en az 3 ay süreyle tıbbi tedaviye yanıt vermeyen anterior diskektomi ve füzyon uygulanan hastalardan oluştu. Hastaların operasyon öncesi ve sonrası servikal bilateral grafileri alınarak, 1-3-6. ve 12. ay sonunda kemik mineral yoğunluğu, VAS skor değerleri, Boyun Engellilik İndeksi, Ishihara indeksi ve SF-36 değerlendirme sonuçları belirlenerek karşılaştıııldı.

\section{Bulgular}

Çalışmada kaynama oranı \%95,6 bulundu 3. ayda sigara içmeyen grupta kaynama oranı \%45, 6.ayda
$\% 65,12$. ayda \%100'e ulașıldı. Sigara içen grupta 3.ayda kaynama oranı $\% 35,6$. ayda $\% 55,12$. ayda ise \% 85 bulundu. Ishihara indeksi değerlerindeki değişim ile hastaların yaşam standardı ve fonksiyonel sonuçlar arasında istatistiksel olarak anlamlı ilişki gözlendi. Hastalarda fonksiyonel sonuçlar ile servikal indeks kıyaslanarak, servikal indeksin anlamlı bir şekilde düzeltilmesi ile fonksiyonel sonuçlarda anlamlı bir iyileşme izlendi.

\section{Sonuç}

Günümüzde orta hat yerleșimli servikal disk hernilerinde en uygun girişim anterior yaklaşımdır. Füzyonlu ya da füzyonsuz yapılabilecek bu girişim hastanın stabilite sorununa göre karar verilecek bir durumdur. Otogreft, allogreft, kafes ya da plak-vida uygulama sonuçları, uzun dönem takiplerde sonuçların karşılaştırmasını gerekli kılmaktadır. Radyolojik incelemelerde servikal omurganın sagital plandaki eğiminde düzleşme veya kifotik deformite varsa posterior girişim ile yer yer füzyon olmuş spondilotik omurgada sagital deformiteyi düzeltmenin güç olması, mevcut olan kifotik deformiteyi artırması nedeniyle posterior servikal dekompresyon uygulanamaz hale gelmektedir. 
Anahtar Kelimeler: Anterior servikal diskektomi, füzyon, kemik mineral yoğunluğu, Ishihara indeksi

\section{Abstract}

\section{Objective}

The aim of this study is to compare the radiological and clinical results of patients who underwent anterior cervical discectomy and fusion, and to determine the relationship between fusion formation and bone mineral density.

\section{Materials and Methods}

A total of 23 patients, who were admitted to the study with a diagnosis of cervical degenerative disc disease and cervical spondylosis at a Faculty of Medicine Orthopedics and Traumatology clinic, were included in the study. The cases consisted of patients who underwent anterior discectomy and fusion, and did not respond to medical treatment for at least 3 months. Cervical bilateral radiographs of patients were taken before and after the operation and bone mineral density, VAS score values, Neck Disability Index, Ishihara index and SF-36 evaluation results were compared at the end of the 1st, 3rd, 6th and 12th months.

\section{Results}

In the study, the joining rate was found to be $95.6 \%$. In the non-smoking group at the end of the 3rd month, the joining success was reached to $45 \%, 65 \%$ at the 6th month, and $100 \%$ at the 12th month. In the smoker group, the joining success at the 3rd month was $35 \%, 55 \%$ at the 6th month and $85 \%$ at the 12 th month. A statistically significant relationship was observed between the changes in the Ishihara index values and the standard of living of patients and functional results. The functional results were compared with the cervical index, and a significant improvement was observed in the functional results with a significant correction of the cervical index.

\section{Conclusion}

Nowadays, the most suitable intervention is considered to be the anterior approach in midline cervical disc hernias. This intervention, which can be performed with or without fusion, is a situation to be decided according to the patient's stability problem. It can be concluded that autograft, allograft, cage or plate-screw application results require comparison of results in long-term follow-up. Moreover, in radiological examinations, if there is a flattening or kyphotic deformity in the inclination of the cervical spine in the sagittal plane, it is difficult to correct the sagittal deformity in the spondylotic spine, which has been fused in places with posterior intervention, and it increases the existing kyphotic deformity, making posterior cervical decompression impossible.

Keywords: Anterior cervical discectomy, fusion, bone mineral density, Ishihara index

\section{Giriş}

Dejeneratif servikal disk hastalığı ve spondilozis, erişkinlerde sık görülen ancak fizyopatolojisi henüz tam olarak açıklığa kavuşturulamamış bir hastalık grubudur $(1,2)$. Sağlıklı bir omurganın görevi, omurilik ve ilgili sinir yapıları korumak, vücudumuzun dik postürde kalmasını ve her yönde hareketimizi sağlamaktır (3). Birbirine intervertebral diskler ve faset eklemleri ile bağlanan ve paravertebral musküloligamentöz yapılar ile desteklenen omur cisimlerinden oluşan omurga, vücudun dik durmasını sağlayacak ve vücut ağılığını taşıyacak kadar katı, her yönde belirli hareketlere izin verecek kadar hareketli bir yapıya sahiptir (4). Yük taşıma, hareketi sağlama ve hareketi kısıtlama gibi birbiri ile çelişen önemli görevleri olan omurganın, bu karmaşık yapısı yaşam sürecinde sağlıklı bir şekilde korunamamaktadır (5). Doğal yaşlanma süreci ile başlayan dejeneratif değişikler, omurganın bazı fonksiyonlarını sağlıklı olarak yapmasını engellemekte ve çeşitli hastalıklara yol açmaktadır (6).
Klinik gözlemler, özellikle son zamanlarda füzyon yapılan segmentin altında veya üstünde ortaya çıkan, yeni dejeneratif süreçler üzerine yoğunlaşmıştır. Füzyon seviyesinin alt veya üst segmentinde ortaya çıkan dejeneratif süreç "komşu segment hastalığı" olarak isimlendirilmiş, füzyon sonrası intersegmental hareketin ortadan kalkması ile alt ve üst segmentlerde artmış olabilecek yük, komşu segment dejenerasyonunun patogenezinde sorumlu tutulmuştur (7). Servikal dejeneratif disk hastalığının cerrahi tedavisinde anterior servikal diskektomi ve füzyon yaygın olarak uygulanmaktadır. Cerrahi esnasında disk mesafesine konulan kafesler içlerine yerleştirilen otogreft ve allogreftler biyomekanik destek sağlayarak füzyon oluşumuna yardımcı olmaktadır (8). Plak uygulamasının füzyon oranlarını arttırdığı bildirilmiştir. Füzyonun sağlanması, bu cerrahinin birincil amacıdır. Bu cerrahi yöntemin diğer yararları; servikal foraminal yüksekliğin ve fizyolojik lordozun sağlanmasıdır (9). Yapılan bir çalışmada, kemik mineral yoğunluğunun lomber bölgede uygulanan pedikül vidasının tutunma gücü 
ile yakından ilişkisi olduğu gösterilmiş ve $0.674 \mathrm{gr} / \mathrm{cm}$ altındaki kemik mineral yoğunluğu değerlerinin posterior lumbar interbody füzyon uygulanan hastalarda artmış kaynamama oranlarına neden olduğu belirtilmiştir (9).

Bu çalışmanın amacı, anterior servikal diskektomi ve füzyon uyguladığımız hastaların radyolojik ve klinik sonuçlarını karşılaştırmak ve füzyon oluşumu ile kemik mineral yoğunluğu arasındaki ilişkiyi saptamaktır.

\section{Gereç ve Yöntem}

\section{Çalışma Kriterleri}

Çalışmaya, Celal Bayar Üniversitesi Tıp Fakültesi Hastanesi Ortopedi ve Travmatoloji kliniğinde servikal dejeneratif disk hastalığı ve servikal spondiloz tanıları ile başvuran toplam 23 hasta dahil edildi. Olgular en az 3 ay süreyle tıbbi tedaviye yanıt vermeyen anterior diskektomi ve füzyon uygulanan hastalardı. Çok seviyeli servikal stenoz, 3 seviyeli disk kompresyonu, diffüz ve yaygın artroz, ileri myelopati, travmatik herniasyon, önceden servikal yakınmaları nedeniyle cerrahi uygulanan ve genel tıbbi durumu kötü olan hastalar çalışma dışı bırakıldı.

Etik onay (Celal Bayar Üniversitesi Tıp Fakültesi Bilimsel Araştırmalar Etik Kurulu, Tarih: 19/05/2011, Sayı: 151) alındıktan tüm olgulara çalışma hakkında genel bilgi verilerek yazılı bilgilendirilmiş imzalanmış onam formu alındı. Ameliyat öncesi hastaların ayrıntılı öyküsü alınarak fizik muayenesi yapılarak kaydedildi. Hastalara polikliniğe başvurduğunda, servikal ön arka, fleksiyonda ve ekstansiyonda direk grafileri çekildi.

Beraberinde hastaların ameliyat öncesi kemik mineral yoğunluğu (KMY) ölçüldü. Hastalara ameliyat öncesi Vizüel Analog Skoru (VAS), boyun engellilik indeksi (BDi), kısa form 36 (SF-36) formu dolduruldu. Hastalara ameliyat sonrası 2.hafta, 1.ay, 3.ay,6. ve 12.ay da SF-36 formu. Hastaların servikal sagital postür değerlendirmesi için Ishihara indeksi kullanıldı (10). Ishihara indeksi ameliyat öncesi, ameliyat sonrası 1-3-6. ve 12. aylarda ölçüldü (11-14).

\section{Cerrahi Teknik}

Hastalara ameliyat öncesi tek doz sefazolin sodyum $50 \mathrm{mg} / \mathrm{kg} / \mathrm{gün}$ intra venöz yoldan verildi. Cilt, cilt altı geçildikten sonra platisma fasyası cilt kesisine paralel olarak insize edildi. Sonra platisma kası vertikal olarak disseke edildi. Ekartasyonun ardından bir enjektör ucu ile disk aralığına girilerek floroskopi kontrolü ile seviye kontrolü yapıldı. Daha sonra servikal diskektomi uygulandı. İntervertebral eklemdeki ve di- ğer osteofitik yapılara eksizyon uygulandı. Üst ve alt vertebra korpuslarına Caspar distraktörüne ait çiviler yerleştirildi. Sonrasında distraksiyon uygulanarak diskektomi uygun şekilde tamamlandı. Füzyona zemin hazırlamak için, end platetlerde kanama olana kadar kıkırdak yapılar kürete edildi. Uygun servikal kafes boyu belirlendikten sonra yaklaşı $1 \mathrm{~cm}$ 'lik longitudinal insizyon ile anterior iliak kanattan spongiöz kemik otogrefti alındı. Alınan otogreftler daha önceden belirlenmiş olan servikal kafes içine ve disk mesafesine yerleştirildi. Skopi kontrolü yapıldı. Daha sonra, servikal kafes uygulanan disk seviyesinin bir alt ve bir üst vertebrasını içine alacak şekilde plak-vida sistemi ile resim 1 de görüldüğü gibi fiksasyon yapıldı.

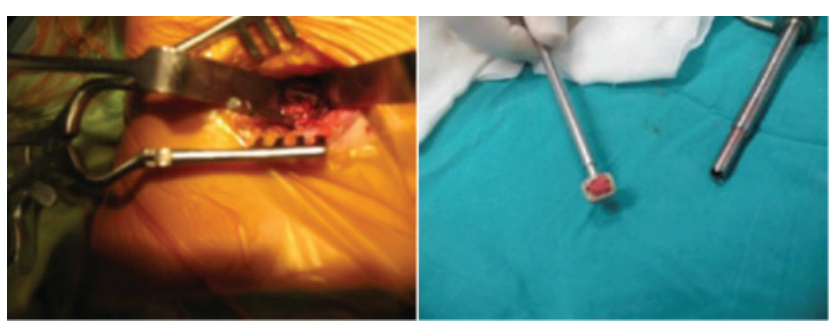

Resim 1

Servikal kafes içerisine otogreftlerin yerleştirilmesi (sağ), Disk aralığına servikal kafes ile otogreft yerleştirilmesi (sol)

Kullanılan plaklar statik kilitli plaklar özellikte olup boyutları 25-45 mm arasında değişmekteydi. Kullanılan kafes otogreft ile doldurulduktan intervertebral alana yerleştirildi. Kafes yerine takılmadan önce uygun boy için deneme boylarına sahipti. Bu işlemlerden sonra skopi kontrolü yapıldı. Cerrahi saha yaklaşık 1000 cc izotonik ile yıkandı. Minivac dren sistemi yerleştirildi. Katlar usulüne uygun kapatıldı. Hastalara servikal kolar takıldı.

Ameliyat sonrası hastalara 24 saat boyunca antibiyotik proflaksisi uygulandı. Drenler cerrahi sonrası 48.saatte çekildi. Serviste ağrı kontrolü, gelen idrar takibi ve tansiyon durumuna göre IV sıvı desteği yapıldı. Ameliyat sonrası 3. saatte sıvı gıdalara başlandı ve 6 saat boyunca sıvı gıdalar ile devam edildi. Hastalarda yutma güçlüğü ve ses kısıklığı açısından ayrıca takip uygulandı. Veriler kaydedildi. Dren çekildikten sonra ameliyat sonrası kontrol radyografileri çekildi. Taburculuk sonrası ikinci haftada sütürler alındı.

\section{İstatistiksel Analiz}

Çalışmanın istatistiksel analizleri SPSS 20.0 programı ile gerçekleştirildi. Kategorik veriler frekans (yüzde oranı), sürekli sayısal veriler ortalama \pm SS şeklinde sunuldu. Sayısal verilerin normal dağılıma uygunluğu Shapiro-Wilk yöntemi ile test edildi. İki bağımsız grup 
karşılaştırması için Mann-Whitney U, tekrarlı ölçümler için Wilcoxon işaretli sıra sayıları testi ve Friedman iki-yönlü varyans analizi kullanıldı. Tip-ı hata oranı \%5 alınarak p<0,05 değeri istatistiksel olarak anlamlı kabul edildi.

\section{Bulgular}

Çalışmada 11 bayan, 12 erkek olmak üzere 23 hasta mevcuttu. Erkek hastaların ortalama yaşı 55,2 (4261), bayan hastaların ortalama yaşı 65,5 (48 - 69) yıl idi. Hastaların ortalama takip süresi 14 ay (12 - 28) idi. Hastalarda ortalama KMY indeksi 0,9 $90,25(0,65-$ $1,15)$ idi.

15 hastaya (8 hasta C4-5, 7 hasta C5-6) tek seviyeli, 8 hastaya iki seviyeli (3 hasta C3-4 ve C4-5, 3 hasta C4-5 ve C5-6, 2 hasta C5-6 ve C6-7) plaklı anterior servikal diskektomi ve füzyon uygulandı. Ortalama cerrahi süresi 75 dk (65-120) idi. Füzyon sahasında kaynama kriteri olarak, anterior posterior korteksler arasında sentinental kemik spiküllerinin görülmesi, kafes ve plak arasında lüsens alanlarının kaybolması, fleksiyon ekstansiyon grafilerinde 2 dereceden daha az hareketin olması ve kalıcı yeterli yüksekliğin sağlaması durumunda füzyonun tamamlandığını gösteren bulgular olarak kabul edildi. Tüm hastaların kaynama oranı \%95,6 (n=21 kaynama olan, n=2 kaynama olmayan) idi. Radyolojik olarak kaynama saptanan olgularda ortalama kaynama süresi 12 hafta idi. 3. ayda sigara içmeyen grupta $(n=13)$ kaynama oranı \%45, 6.ayda \%65, 12,ayda \%100 idi. Sigara içen grupta ( $n=10)$ 3.ayda kaynama oranı \%35, 6 ayda \%55, 12. ayda ise \% 85 idi.

Sigara kullanma öyküsü olan 10 hastanın ikisinde (\%20) kaynamama saptanırken kullanmayan 13 hastanın hiçbirinde kaynamama izlenmemiştir. Sigara kullanımı ile kaynamama arasında anlamlı bir ilişki görülmemiştir ( $p=0,952)$. Kaynama gecikmesi olan

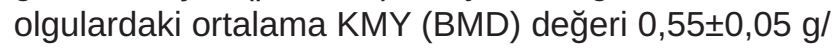
cm2 iken kaynaması olan olgulardaki ortalama KMY

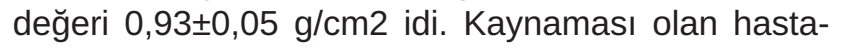
larda KMY değerleri, kaynama gecikmesi olan hastalarınkine göre daha yüksekti $(p=0,023)$. Kaynama saptanan ve saptanmayan hastalarda fonksiyonel sonuçlar açısından 1-3 ve 6. ay izlemleri açısından istatistiksel olarak anlamlı bir fark (1.ay $(p=0.318)$, 3.ay $(p=0.287)$, 6.ay $(p=0.253))$ saptanmaz iken 12. ay izlemleri arasında anlamlı fark saptanmadı $(p=0,014)$. Hastaların ameliyat öncesi ve sonrası yaşam kalitesi arasında anlamlı fark gözlendi $(p<0,05)$. Ameliyat olan hastaların tüm yaşam standartları artış gösterdi (mental sağlık hariç diğer SF-36 boyutları için $p<0,05)$. Hastaların ameliyat öncesi ölçülen Ishihara indeksi ortalama 9,20 0 0,84 (8,3-10,5) iken ameliyat sonrası 3.ay bu değer 15,62 $\pm 1,56(13,9-17,9)$ olarak saptandı $(p=0,002$, genel $p=0,016)$. Hastalara ameliyat öncesi ve ameliyat sonrası 1-6. ve 12. aylarda yapılan VAS değerleri değişimi anlamlı olarak azaldı $(p<0,001)$. Trabeküler kemik içindeki vida uzunluğunun ve cinsiyetin kaynama üzerine anlamlı etkisi bulunmadı $(p>0,05)$. Bulgulara ait sonuçlar Tablo.1'de detaylı olarak sunuldu.

\section{Tartışma}

Dejeneratif disk hastalığı, travma, akut disk hernisi ve ossifiye PLL tek veya çok seviyeli spinal kanal darlığına neden olmaktadır $[15,16]$. Radyolojik incelemelerde servikal omurganın sagital plandaki eğiminde düzleşme veya kifotik deformite varsa; posterior girişim ile yer yer füzyon olmuş spondilotik omurgada sagital deformiteyi düzeltmenin güç olması, mevcut olan kifotik deformiteyi artırması nedeniyle posterior servikal dekompresyon uygulanamaz hale gelmektedir [17]. Servikal myelopati ile beraber servikal lordozu bozulmuş veya kifotik deformite gelişmiş olgular için anterior diskektomi veya korpektomi ile füzyon, sagital deformiteyi düzelttiği gibi nöral elemanlar üzerindeki bası etkisini de ortadan kaldırmaktadır [18]. Özellikle fleksiyon hareketinde plak ve grefte binen yük azalır [19]. Bu durum füzyon gelişme olasılığını azaltır. Uzun segment plak ve greft kullanımının beraberinde getirdiği komplikasyonları azaltmak için uygun olgularda dekompresyon amacıyla yapılan çoklu seviye korpektomi yerine, çoklu seviye diskektomi yaygın kullanılan bir yöntem haline gelmiştir [10]. Çoklu seviye diskektominin, plak-vida yetmezliği, uzun greft kullanımına bağlı greft kayması veya greftin kaynamaması gibi komplikasyonları azaltacağı düşünülmüştür [10]. Yapılan biyomekanik çalışmalarda 3 seviye korpektomiden sonra yerleştirilen greftin alt ve üst uçlarında, tek seviye diskektomi sonrası yerleştirilen grefte göre daha hareketli olduğu doğrulanmıştır [20]. Ayrıca plak vida sistemi, önünde bir bariyer olarak greftin anteriora doğru kayma riskini ortadan kaldırır ve anterior servikal plağın rotasyonunun anlık eksenini anteriora doğru kaydırır. Bu durumda greft üzerine binen stres ve greftin çökme riski azalır [21].

Tek seviyeli diskektomilerde füzyon oranı çok yüksektir. Ancak çoklu seviye diskektomilerde çoklu seviye korpektomilerde olduğu gibi füzyon oranları seviye sayısı arttıkça giderek azalmaktadır [22]. Birçok çaışmada servikal diskektomi sonrası omurlar arasına yerleştirilen trikortikal otogreftler, allogreftlere göre daha fazla radyolojik kaynama ve daha az greft çökme oranına sahiptir [23]. Otogreftler genellikle iliak kemikten sağlanmaktadır ve halen anterior servikal 


\begin{tabular}{|c|c|c|c|c|c|c|c|}
\hline \multirow{2}{*}{\multicolumn{2}{|c|}{ Özellikler }} & \multirow[t]{2}{*}{ Pre-op } & $\begin{array}{l}\text { Post-op } \\
\text { 1.ay }\end{array}$ & $\begin{array}{l}\text { Post-op } \\
\text { 3.ay }\end{array}$ & $\begin{array}{l}\text { Post-op } \\
6 . a y\end{array}$ & $\begin{array}{l}\text { Post-op } \\
\text { 12.ay }\end{array}$ & \multirow[t]{2}{*}{ p } \\
\hline & & & n (\%) & n (\%) & n (\%) & n (\%) & \\
\hline $\begin{array}{l}\text { Kaynama } \\
\text { oranı (Sigara } \\
\text { içen) }\end{array}$ & \multicolumn{2}{|c|}{$\%$} & $\% 23$ & $\% 35$ & $\% 55$ & $\% 85$ & 0,684 \\
\hline $\begin{array}{l}\text { Kaynama } \\
\text { oranı (Sigara } \\
\text { içmeyen) }\end{array}$ & \multicolumn{2}{|c|}{$\%$} & $\% 38$ & $\% 45$ & $\% 65$ & $\% 100$ & 0,521 \\
\hline \multicolumn{8}{|c|}{ Ortalama $\pm S S$} \\
\hline $\begin{array}{l}\text { KMY } \\
\text { Kaynaması } \\
\text { olmayan }\end{array}$ & $\mathrm{gr} / \mathrm{cm}^{2}$ & $0,52 \pm 0,04$ & & $0,55 \pm 0,05$ & & & 0,815 \\
\hline $\begin{array}{l}\text { KMY } \\
\text { Kaynaması } \\
\text { olan }\end{array}$ & $\mathrm{gr} / \mathrm{cm}^{2}$ & $0,54 \pm 0,05$ & & $0,93 \pm 0,07$ & & & 0,023 \\
\hline \multirow[t]{8}{*}{ SF-36 } & $\begin{array}{l}\text { Fiziksel } \\
\text { fonksiyon }\end{array}$ & $47,39 \pm 11,46$ & & $71,95 \pm 14,04$ & & & $<0,001$ \\
\hline & $\begin{array}{l}\text { Fiziksel rol } \\
\text { güçlüğü }\end{array}$ & $23,91 \pm 19,18$ & & $68,47 \pm 24,09$ & & & $<0,001$ \\
\hline & Ağrı & $17,78 \pm 14,67$ & & $70,95 \pm 23,92$ & & & $<0,001$ \\
\hline & $\begin{array}{l}\text { Genel } \\
\text { sağlık }\end{array}$ & $48,86 \pm 9,06$ & & $59,56 \pm 17,14$ & & & 0,007 \\
\hline & Vitalite & $47,17 \pm 11,36$ & & $54,13 \pm 8,34$ & & & 0,012 \\
\hline & $\begin{array}{l}\text { Sosyal } \\
\text { fonksiyon }\end{array}$ & $45,65 \pm 14,89$ & & $65,76 \pm 23,60$ & & & 0,009 \\
\hline & $\begin{array}{l}\text { Emosyonel } \\
\text { rol güçlüğü }\end{array}$ & $36,23 \pm 22,27$ & & $71,01 \pm 30,65$ & & & $<0,001$ \\
\hline & $\begin{array}{l}\text { Mental } \\
\text { sağlık }\end{array}$ & $51,82 \pm 11,15$ & & $52,34 \pm 6,13$ & & & 0,742 \\
\hline $\begin{array}{l}\text { Ishihara } \\
\text { Indeksi }\end{array}$ & skor & $9,20 \pm 0,84$ & $15,73 \pm 0,76$ & $15,62 \pm 1,74$ & $15,57 \pm 1,65$ & $15,69 \pm 1,56$ & 0,016 \\
\hline BEi & skor & $42,08 \pm 2,31$ & $29,56 \pm 4,88$ & $22,04 \pm 8,31$ & $16,369 \pm 6,87$ & $9,91 \pm 8,14$ & $<0,001$ \\
\hline $\begin{array}{l}\text { VAS (kaynama } \\
\text { olmayan) }\end{array}$ & skor & $8,94 \pm 2,61$ & $7,74 \pm 3,72$ & $5,23 \pm 1,06$ & $4,16 \pm 2,32$ & $2,00 \pm 1,52$ & $<0,001$ \\
\hline $\begin{array}{l}\text { VAS (kaynama } \\
\text { olan) }\end{array}$ & skor & $8,32 \pm 2,56$ & $7,56 \pm 1,74$ & $5,22 \pm 1,06$ & $2,19 \pm 0,57$ & $0,08 \pm 0,01$ & $<0,001$ \\
\hline Vida uzaklığı & $\mathrm{mm}$ & & $3,86 \pm 0,82$ & $3,91 \pm 0,80$ & $4,00 \pm 0,86$ & $4,04 \pm 0,94$ & 0,436 \\
\hline
\end{tabular}

füzyon için ilk tercihtir [24]. Korpektomi yapılan olgularda fibular allogreft ile $\% 41$, otogreft ile $\% 27$ ye ulaşan nonfüzyon oranları bildirilmiştir [22].

Anterior girişim yolunu tercih eden cerrahlar ise tartışmalarını daha çok füzyon üzerinde yoğunlaştır- maktadır. Anterior diskektomi sonrası disk aralığına otogreft, allogreft ya da "cage" denilen kafesler konularak füzyon amaçlanmakta ve plak-vida sistemleri ile omurga gövdesinde çökmeleri önlemek ve omurganın stabilizasyonunu korumak hedeflenmektedir. Ancak bazı serilerde füzyonsuz basit anterior diskektominin, 
komplikasyonu az ve etkili bir yöntem olduğu söylenmektedir. Ferynhough ve arkadaşları 64 hastada füzyonsuz anterior basit diskektomi uygulamış, sonuçları oldukça iyi bulmuştur [10]. Buna karşın füzyonlu anterior diskektomi uygulayan gruplar, daha etkin ve dayanıklı füzyon materyali konusunda tartışmaktadır. Bunun en son örneği otogreft, allogreft ve kafes sistemleri yanında hidroksiapatit seramikten yapılmış füzyonlardır [22].

Yapılan bir çalışmada, anterior diskektomi ve füzyon sonrası sigara içmeyen hastalarda füzyon oranları 3.ayda \%42 olarak bulunmuştur. 3.ayda bütün hastalardaki kaynama oranları ise \%16 olarak saptanmıştır. Cerrahiden 6 ay sonra sigara içmeyen grupta kaynama oranı $\% 85$ olarak görülürken, bütün hasta grubunda 6.ayda kaynama oranı $\% 45$ olarak saptanmıştır [25].

Bizim çalışmamızda ise kaynama oranı \%95,6 bulunmuştur. 3. ayda sigara içmeyen grupta kaynama oranı \%45, 6.ayda \%65, 12. ayda \%100'e ulaşmıştır. Sigara içen grupta 3.ayda kaynama oranı \%35, 6. ayda $\% 55,12$. ayda ise $\% 85$ bulunmuştur. Kaynama oranları ile ilişsili sonuçlar literatür ile paralellik göstermektedir. Çalışmamızda, boyun engellilik indeksi, VAS, fonksiyonel ve yaşam standardı açısından istatistiksel olarak ameliyat öncesi ve sonrası arasında anlamlı bir fark saptanmıştır. Bu bulgular, yapılan diğer çalışmaların sonuçları ile uyum göstermektedir $[10,26,27]$. Çalışmada, Ishihara indeksi değerlerindeki değişim ile hastaların yaşam standardı ve fonksiyonel sonuçlar arasında istatistiksel olarak anlamlı ilişki gözlenmiştir. Hastalarda fonksiyonel sonuçlar ile servikal indeks kıyaslanmış, servikal indeksin anlamlı bir şekilde düzeltilmesi ile fonksiyonel sonuçlarda anlamlı bir iyileşme izlenmiştir $[10,28]$. Bu açıdan bulgularımız literatür ile uyum göstermektedir. Şekil 1'de opere edilmiş bir olgumuzun preop ve postop filmleri görülmektedir. Yapılan çalışmalar, sigara kullanımının füzyon üzerine olumsuz etkileri olduğunu göstermiştir $[10,29]$. Sigara içen hastalarda kaynamama oranı yaklaşık olarak \%15 olarak gösterilmiştir. Fakat takiplerde 1.yılın sonunda hastaların hepsinde kaynama gözlemlenmiştir $[10,30]$. Çalışmamızda sigaranın füzyon üzerine olumsuz anlamlı etkisini gözlemlenmemiştir. Fakat bunun nedeninin mevcut hasta sayısının göreceli olarak az olması düşünülmüştür. Çalışmamızda cinsiyet farkııı̆ının füzyon üzerine anlamlı etkisini saptanmamış, ancak bu sonuç ile ilgili bilgiye literatürde rastlanmadığından karşılaştırma yapılamamıştır.

Anterior servikal diskektomi ve füzyon uygulanan hastalarda kemik grefti uygulamasında temel amaç, biyomekanik destek sağlanması, sağlanmış olan foraminal yüksekliğin devamlılığın sürdürülmesi, servikal lordozun sağlanması ve osteointegrasyondur. Bununla beraber, sentetik donör materyalleri, donör sahadaki komplikasyonların azaltmakta iken hastanın hastanede kalış süresini kısaltmaktadır [4]. Bu çaIışmanın randomize kontrollü olmaması, olgu sayısının göreceli olarak az olması ve takip süresinin kısa olması çalışmanın kısıtlılıklarındandır. Tüm bunlara rağmen, erken dönemdeki bu sonuçlar, plaklı anterior servikal diskektomi ve füzyon uygulamasının uygun hasta grubunda, başarılı klinik ve radyolojik iyileşmeler sağladığını göstermektedir. Ayrıca daha önce literatürde araştırılmayan, kemik mineral yoğunluğu ve füzyon arasındaki anlamlı ilişki ortaya konmuştur.

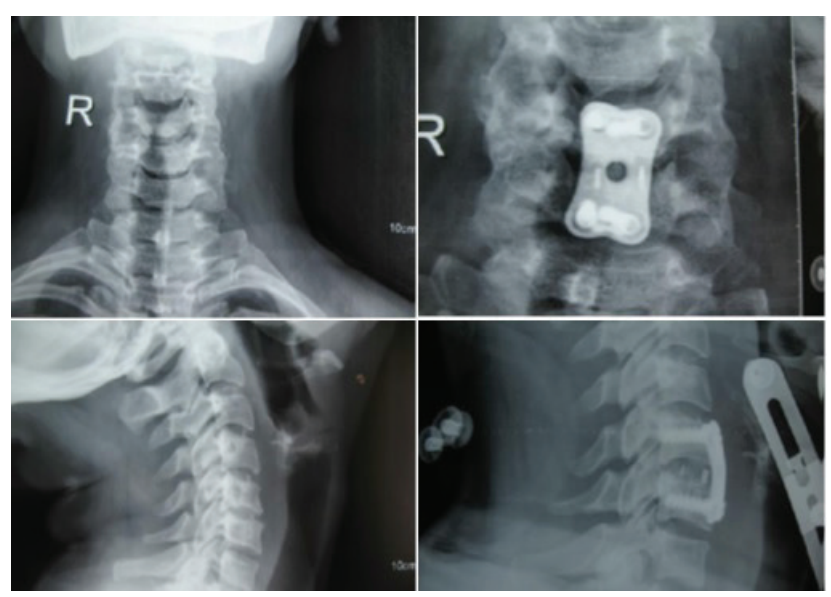

Şekil 1

48 yaş erkek bir olgunun pre-op radyografileri (sol), aynı olgunun C5-6 anterior diskektomi, dekompresyon füzyon sonrası radyografileri (sağ)

Bu çalışmanın çeşitli limitasyonları bulunmaktadır. Çalışma tasarımının randomize kontrollü olarak hazırlanamaması ve olgu sayısının göreceli olarak az olması önemli zayıf yönler olarak görülebilir. Ayrıca, takip süresinin kısa olması da diğer bir kısıtlılık olarak karşımıza çıkmaktadır. Tüm bunlara rağmen, erken dönemde elde edilen sonuçlar, plaklı anterior servikal diskektomi ve füzyon uygulamasının uygun hasta grubunda, başarılı klinik ve radyolojik iyileşmeler sağladığını göstermektedir. Ayrıca, daha önce literatürde araştırılmayan KMY (BMD) ve füzyon arasındaki anlamlı ilişki ortaya konulmuştur.

\section{Sonuç}

Servikal spondilozda, cerrahi yaklaşım türünü belirlerken hastanın yaşı, hastalıklı seviye sayısı, problemin segmenter ya da diffüz nitelikli olması, lordoz miktarı, spinal korddaki hasarın düzeyi, hastanın bizzat 
kendisine ait risk faktörleri gibi antiteler göz önünde bulundurulmalı ve ona göre seçim yapılmalıdır. Kliniğimizde bu seçim yapılırken en yalın şekli ile eğer hastalıklı seviyelerdeki problem, segmenter nitelik taşıyor ise sadece problemli seviyelere anterior servikal diskektomi, otojen iliak greftleme ve anterior plaklama yapılmaktadır. Günümüzde orta hat yerleşimli servikal disk hernilerinde en uygun girişim anterior yaklaşımdır. Füzyonlu ya da füzyonsuz yapılabilecek bu girişim hastanın stabilite sorununa göre karar verilecek bir durumdur. Otogreft, allogreft, kafes ya da plak-vida uygulama sonuçları, uzun dönem takiplerde sonuçların karşılaştırmasını gerekli kılmaktadır. Lateral veya intraforaminal yerleşimli hernilerde posterior veya anterior cerrahi yaklaşımların her ikiside uygun görünmekte, cerrahın tercihi ve hastaların her birinin ayrı ayrı değerlendirilmesi karar vermede etkin olmaktadır. Radyolojik incelemelerde servikal omurganın sagital plandaki eğiminde düzleşme veya kifotik deformite varsa posterior girişim ile yer yer füzyon olmuş spondilotik omurgada sagital deformiteyi düzeltmenin güç olması, mevcut olan kifotik deformiteyi artırması nedeniyle posterior servikal dekompresyon uygulanamaz hale gelmektedir. Bu gibi olgularda anterior girişim düşünülmelidir. Cerrahide dekompresyon sağlandıktan sonra traksiyon yapılmadan greftin uzunluğu ölçülür. Greftin uzunluğu normal alınan ölçüden 2 $\mathrm{mm}$ kadar fazla olması hem son plaklara kompresyon altında temas sağlayacağı için füzyon şansını artırır hem de servikal yapıya lordotik açı vermesini sağlar. Cerrahi sırasında kifotik bozukluğun tamamen düzeltilmesi veya aşırı lordotik açı verilmesi beraberinde çeşitli komplikasyonlara neden olur (spinal kord hasarı, servikal instabilite vb.). Bu nedenle kifozun en azından lordoz yerine düz bir hale getirilmesi veya lordotik yapıya aşırı lordotik açı verilmemesi daha gerçekçi bir yaklaşım olacaktır.

\section{Kaynaklar}

1. Zileli M, Özer F. Omurilik ve omurga cerrahisi. Meta Basım Matbaacılık Hizmetleri. İmir 2002; 739-46.

2. Brigham CD, Tsahakis PJ. Anterior cervical foraminotomy and fusion. Surgical technique and results. Spine 1995;20(7):76670.

3. Dasgupta R. Re-reading the salaryman in Japan: Crafting masculinities. Routledge 2012.

4. Kuran O. Columma Vertebralis, In; Sistematic Anatomy (Kuran O, ed), 3. Baskı, Filiz Kitabevi, 1993;74.

5. Dvorak J, Sandler A. Historical Perspective Hubert von Luschka: Pioneer of Clinical Anatomy. Spine 1994;19(21):2478-82.

6. Payne EE, Spillane JD. The cervical spine an anatomico-pathological study of 70 specimens (using a special technique) with particular reference to the problem of cervical spondylosis. Brain 1957:80(4):571-96.

7. Özbek Z, Özkara E, Yağmur i, Arslantaş A. Servikal Komşu Segment Hastalığı. Osmangazi Tıp Dergisi 2018;40(2):101-6.

8. Grasso G, Landi A. Long Term Radiological And Clinical Evaluation Of Simple Cervical Discectomy Versus Anterior Fusion
With Peek Cage. 2018;9(2):87-92

9. Bradford DS, Zdeblick TA. The spine.Lippincott Williams \& Wilkins, 2004.

10. Fernyhough JC, White J,LaRocca H. Fusion rates in multilevel cervical spondylosis comparing allograft fibula with autograft fibula in 126 patients. Spine 1991;16(10):561-4.

11. Birch J. Efficiency of the Ishihara test for identifying red-green colour deficiency. Ophthalmic and Physiological Optics 1997;17(5):403-8.

12. Ware J, John E. SF-36 health survey. Lawrence Erlbaum Associates Publishers,1999;1227-46.

13. Cleland JA, Fritz JM, Whitman JM, Palmer JA. The reliability and construct validity of the Neck Disability Index and patient specific functional scale in patients with cervical radiculopathy. Spine 2006;31(5):598-602.

14. Cline ME, Herman J, Shaw ER, Morton RD. Standardization of the visual analogue scale. Nursing research 1992.

15. Abbed KM, Coumans JV. Cervical radiculopathy: pathophysiology, presentation, and clinical evaluation. Neurosurgery 2007;60:1-28.

16. Hyong IH, Kim HS, Lee SY. The effect of immediate pain and cervical ROM of cervical pain patients on stretching and manipulation. The Journal of Korean Physical Therapy 2009;21(4):17.

17. Kaner T, Özer AF. İatrojenik Spinal Deformiteler. Türk Nöroşirürji Dergisi 2013;23(2):74-82.

18. Chang SW, Kakarla UK, Maughan PH, DeSanto J, Fox D, Theodore $\mathrm{N}$, et al. Four-level anterior cervical discectomy and fusion with plate fixation: radiographic and clinical results. Neurosurgery 2010;66(4):639-47.

19. Isomi T, Panjabi MM, Wang JL, Vaccaro AR, Garfin SR, Patel T. Stabilizing potential of anterior cervical plates in multilevel corpectomies. Spine 1999;24(21):2219.

20. DiAngelo DJ, Foley KT, Vossel KA. Rampersaud YR, Jansen $\mathrm{TH}$. Anterior cervical plating reverses load transfer through multilevel strut-grafts. Spine 2000; 25(7):783-95.

21. Galler RM, Dogan S, Fifield MS, Bozkus H, Chamberlain RH, Sonntag VK,et al. Biomechanical comparison of instrumented and uninstrumented multilevel cervical discectomy versus corpectomy. Spine 2007;32(11):1220-6.

22. Samartzis D, Shen FH, Goldberg EJ, An HS. Is autograft the gold standard in achieving radiographic fusion in one-level anterior cervical discectomy and fusion with rigid anterior plate fixation? Spine 2005;30(15):1756-61.

23. Ryu SI, Lim JT, Kim SM, Paterno J, Kim DH. Comparison of the biomechanical stability of dense cancellous allograft with tricortical iliac autograft and fibular allograft for cervical interbody fusion. European Spine Journal 2006;15(9):1339-45.

24. Roberts S, Urban JP, Evans H, Eisenstein SM. Transport properties of the human cartilage endplate in relation to its composition and calcification. Spine 1996; 21(4):415-20.

25. Boger DC. Traction device to improve CT imaging of lower cervical spine. American journal of neuroradiology.1986;7(4):719-21.

26. Baleriaux D, Noterman J, Ticket L. Recognition of cervical soft disk herniation by contrast-enhanced CT. American Journal of Neuroradiology 1983;4(3):607-8.

27. Jahnke R, Hart B. Cervical stenosis, spondylosis, and herniated disc disease. Radiologic Clinics of North America 1991;29(4):777-91.

28. Daniels DL, Grogan JP, Johansen JG, Meyer GA, Williams AL, Haughton VM. Cervical radiculopathy: computed tomography and myelography compared. Radiology 1984;151(1):109-13.

29. Fukushima T, Ikata T, Taoka Y, Takata S. Magnetic resonance imaging study on spinal cord plasticity in patients with cervical compression myelopathy. Spine 1991;16(10):534-8.

30. Mann KS, Khosla VK, Gulati DR. Cervical spondylotic myelopathy treated by single-stage multilevel anterior decompression: A prospective study. Journal of neurosurgery, 1984;60(1):81-7. 